\title{
Transplantation of alveolar type II cells stimulates lung regeneration during compensatory lung growth in adult rats
}

\author{
Hironobu Wada, MD, PhD, ${ }^{\mathrm{a}}$ Shigetoshi Yoshida, $\mathrm{MD}, \mathrm{PhD},{ }^{\text {a }}$ Hidemi Suzuki, MD, PhD, ${ }^{\mathrm{a}}$ \\ Yuichi Sakairi, MD, PhD, ${ }^{\text {a }}$ Teruaki Mizobuchi, MD, PhD, ${ }^{a}$ Daisuke Komura, $\mathrm{PhD},{ }^{\mathrm{a}}$ Yasunori Sato, $\mathrm{PhD},{ }^{\mathrm{b}}$ \\ Sana Yokoi, $\mathrm{MD}, \mathrm{PhD},{ }^{\mathrm{c}}$ and Ichiro Yoshino, $\mathrm{MD}, \mathrm{PhD}^{\mathrm{a}}$
}

\begin{abstract}
Objective: It is controversial whether lung regeneration contributes to compensatory lung growth after pulmonary resection in mature individuals. The objectives of this study were to clarify the molecular mechanisms that regulate the process of compensatory lung growth and investigate the influence of transplantation of lung cells enriched in alveolar type II cells on compensatory lung growth.
\end{abstract}

\begin{abstract}
Methods: Serial changes of morphology and gene expression were examined in the remnant right lung after pneumonectomy in adult male Wistar rats. One day after surgery, animals received endotracheal transplants of rat lung cells enriched in alveolar type II cells at a dose of $2.5 \times 10^{6}$ cells. Serial morphologic changes were examined in comparison with pneumonectomy alone. Engraftment of lung cells was validated with a sex-mismatch model.

Results: The alveolar density with mean linear intercept was always lower in pneumonectomized rats than in sham surgical controls for 6 months after surgery. Microarray analysis revealed that multiple genes related to proliferation (but not specific alveolar development) were initially up-regulated and then returned to normal after 1 month. In the pneumonectomized rats with transplantation, the alveolar density was equivalent to that in the sham controls. Engraftment of the transplanted cells from male donors in the alveoli of female recipients was proven by detection of Y-chromosome positive cells and quantified by real-time polymerase chain reaction for the Sry gene. This occurred in pneumonectomized rats but not in sham controls.
\end{abstract}

Conclusions: We postulate that lung cell transplantation stimulates lung regeneration in the remnant lung after pneumonectomy in mature rats. (J Thorac Cardiovasc Surg 2012;143:711-9)

\section{Supplemental material is available online.}

In experimental animals, compensatory lung growth (CLG) is the process that restores weight, volume, DNA, and protein to the remnant lung after major pulmonary resection. ${ }^{1}$ The biological principles that underlie the induction and growth of the lung provide critical information for the field of lung regenerative medicine. CLG depends on the age and size of the animal, and proceeds further in younger and

\footnotetext{
From the Department of General Thoracic Surgery, ${ }^{a}$ Graduate School of Medicine, Chiba University, Chiba, Japan; Clinical Research Center, ${ }^{b}$ Chiba University Hospital, Chiba, Japan; and Cancer Genome Center, Research Institute, Chiba Cancer Center, ${ }^{\mathrm{c}}$ Chiba, Japan.

Supported by Grants-in-aid for Science Research 21791315 (to H.W.) and 19591612 and 90334200 (to S. Yoshida and I.Y.) from the Japanese Ministry of Education, Culture, Sports, Science and Technology; and by grants from Chiba Foundation for Health Promotion and Disease Prevention (to S. Yoshida).

Disclosures: Authors have nothing to disclose with regard to commercial support.

Received for publication July 3, 2011; revisions received Aug 17, 2011; accepted for publication Sept 21, 2011; available ahead of print Oct 31, 2011.

Address for reprints: Hironobu Wada, MD, PhD, Department of General Thoracic

Surgery, Graduate School of Medicine, Chiba University, 1-8-1, Inohana, Chuo-

ku, Chiba 260-8670, Japan (E-mail: hirow-12@umin.ac.jp).

$0022-5223 / \$ 36.00$

Copyright (c) 2012 by The American Association for Thoracic Surgery

doi:10.1016/j.jtcvs.2011.09.024
}

smaller ones. Mechanical stretch and shear stress caused by major pulmonary resection could trigger $\mathrm{CLG},{ }^{1}$ and various endogenous and exogenous growth factors, such as hepatocyte growth factor, ${ }^{2}$ keratinocyte growth factor, ${ }^{3}$ vascular endothelial growth factor, ${ }^{4}$ and retinoic acid, ${ }^{5}$ could accelerate CLG. However, despite many morphometric studies of CLG in animals, the molecular mechanisms that regulate the process are still unknown. Furthermore, it has been controversial whether regeneration of new lung tissue is involved in the process of CLG in mature individuals. ${ }^{1}$

Stem cell populations involved in lung repair and regeneration remain to be clarified. It is controversial whether bone marrow-derived stem cells play a critical role in the regeneration of pulmonary epithelium after lung injury. ${ }^{6}$ No significant contribution to CLG from bone marrow-derived stem cells was demonstrated in the adult mouse model. ${ }^{7}$ Bronchioalveolar stem cells (BASCs), identified as a stem cell population of the distal airways and alveoli in the murine model, have been postulated to proliferate and contribute to CLG after pneumonectomy in mice. ${ }^{8}$ However, the isolation of BASCs is difficult, and the number of BASCs that may be retrieved for therapeutic purposes is limited. Furthermore, a stem cell lineage analogous to BASCs in mice has yet to be identified in human lung.

Alveolar type II cells (ATIIs) act as metabolic regulators of water balance and producers of surfactant proteins to 


$$
\begin{aligned}
& \text { Abbreviations and Acronyms } \\
& \begin{aligned}
\text { ATII } & =\text { alveolar type II cell } \\
\text { BASC } & =\text { bronchioalveolar stem cell } \\
\text { CLG } & =\text { compensatory lung growth } \\
\text { GSEA } & =\text { Gene Set Enrichment Analysis } \\
\text { HE } & =\text { hematoxylin-eosin } \\
\text { Lm } & =\text { mean linear intercept } \\
\text { PCR } & =\text { polymerase chain reaction } \\
\text { PNX } & =\text { left pneumonectomy } \\
\text { Y-FISH } & =\text { fluorescence in situ hybridization } \\
& \text { for Y-chromosome }
\end{aligned}
\end{aligned}
$$

maintain the airspace in alveoli. ATIIs are converted to alveolar type I cells during the repair of lung injury and fetal lung development. ${ }^{9}$ Therefore, the epithelial progenitors responsible for the repair and regeneration of damaged alveoli should be present within the ATII compartment. Endotracheal instillation of ATIIs successfully reversed lung fibrosis in an experimental rat model of bleomycin injury. ${ }^{10}$ Moreover, transplantation of ATIIs derived from human embryonic stem cells recently showed promise as an effective treatment for acute lung injury in adult mice. ${ }^{11}$ ATIIs are more predominant than BASCs among lung cells, and cell therapy using ATIIs is a fascinating concept for lung regenerative medicine.

The first objective of our study was to clarify whether lung regeneration was involved in post-pneumonectomy CLG, and the second objective was to determine whether supplemental transplantation of lung cells enriched in ATIIs could enhance lung regeneration.

\section{MATERIALS AND METHODS}

\section{Experimental Designs and Animals}

All studies were performed according to animal protocols approved by the Institute for Animal Care at Chiba University (approval code A21-112), and all procedures conformed to the National Institutes of Health Guide for the Care and Use of Laboratory Animals. Pathogen-free, 7- to 8-week-old male Wistar rats, weighing 240 to $300 \mathrm{~g}$, were used as adult rats and purchased from Takasugi Experimental Animals Supply Co, Ltd (Saitama, Japan). Two experimental groups were used: One group underwent left pneumonectomy (PNX group), and the other group underwent a simple thoracotomy (sham group). Each group at a designated time point consisted of at least 3 rats.

\section{Surgical Procedure}

Animals were anesthetized by inhalation of isoflurane and intubated via the transoral route after connection to a small-animal ventilator. Rats underwent left thoracotomy under general anesthesia with $2 \%$ isoflurane in inspired oxygen. In the PNX group, the left lung was resected after ligation of the hilus, and the chest was closed followed by immediate suction of the left pleural cavities to apply mechanical stress. In the sham operation group, a simple thoracotomy was performed without application of suction to the left pleural cavity. Three or 7 days, or 1, 3, or 6 months after surgery, both groups of rats were euthanized and the remnant lung was removed en bloc. After determining the wet weight of the lungs, they were instilled with $4 \%$ paraformaldehyde to a pressure of $25 \mathrm{~cm} \mathrm{H}_{2} \mathrm{O}$ followed by tying off the trachea to maintain airway inflation pressure, and the volume of each lung was measured by a water replacement method as described. ${ }^{12}$

\section{Lung Morphometry}

The removed lungs were fixed in $4 \%$ paraformaldehyde, embedded in paraffin, cut into $4-\mu \mathrm{m}$ sections, and stained with hematoxylin-eosin (HE). The mean linear intercept $(\mathrm{Lm})$ value was measured to quantify lung expansion after pneumonectomy as described. ${ }^{13}$

\section{Gene Expression Analysis}

For the PNX group, mRNA was extracted from the left lung as a control and the right lung (caudal lobe) of the same rat. Purified mRNAs were subjected to comprehensive gene expression analysis by microarray (4plex expression array, Roche NimbleGen, Madison, Wis). Genes whose expression level in the right lung was more than twice that of the control left lung were analyzed by Gene Set Enrichment Analysis (GSEA) ${ }^{14}$ to interpret gene expression data at each time point using Pathway Studio (World Fusion Co, Ltd, Tokyo, Japan). Gene ontology terms were referred to by category, and gene sets that shared common molecular functions or biological processes were used. ${ }^{15} P$ values were corrected by the Bonferroni method.

\section{Enrichment of Lung Alveolar Type II Cells}

The protocol for isolation of rat lung cells enriched for ATIIs was previously described. ${ }^{10,16}$ Lung cells were isolated from 8-week-old male Wistar rats, and their viability was assessed by trypan blue (Sigma, St Louis, Mo) exclusion. Freshly isolated cells were evaluated by fluorescence immunostaining of surfactant protein $\mathrm{C}$ and by transmission electron microscopy. Immunofluorescence of ATIIs was determined as follows. The cells were fixed in $4.0 \%$ paraformaldehyde and blocked using $10 \%$ bovine serum and then incubated with primary antibody (surfactant protein C; FL197, dilution 1:100, Santa Cruz Biotechnology, Santa Cruz, Calif) followed by secondary antibody (DyLight 488, dilution 1:5000, Cosmo Bio, Tokyo, Japan) and stained with DAPI. All images were obtained on an Axio Imager Z1 (Carl Zeiss, Oberkochen, Germany) equipped with AxioCam (Carl Zeiss) using a $10 \times$ ocular lens and a $10 \times$ and an oil immersion $63 \times$ objective lens, and analyzed with Axio Vision (Carl Zeiss). Transmission electron microscopy of ATIIs was consigned to Hanaichi UltraStructure Research Institute (Aichi, Japan).

\section{Transplantation Procedure}

One day after pneumonectomy or sham operation, 8-week-old female rats received endotracheal transplants of $2.5 \times 10^{6}$ lung cells suspended in 200 or $400 \mu \mathrm{L}$ of sterile saline. Rats were euthanized 7 days or 1 or 3 months after surgery, and morphologic analysis was performed as above.

\section{Fluorescence In Situ Hybridization for Y-Chromosome Analysis}

Fluorescence in situ hybridization for Y-chromosome (Y-FISH) with gender mismatch transplantation between male donors and female recipients has been described ${ }^{10}$ using Cy3-labeled DNA probes specific for the rat Y chromosome (Chromosome Science Lab, Hokkaido, Japan).

\section{Real-time Polymerase Chain Reaction}

Total DNA was extracted from resected caudal lobes by using DNeasy Blood and Tissue Kits (Qiagen, Tokyo, Japan) according to the manufacturer's directions. To evaluate the engraftment of donor lung cells, real-time polymerase chain reaction (PCR) was performed. The PCR oligonucleotide primers used for the sex-specific region of the $\mathrm{Y}$ chromosome (Sry) were 5'-GCT-CAA-CAG-AAT-CCC-AGC-AT-3' (forward) and 
5'-TTT-GTT-GAG-GCA-ACT-TCA-CG-3' (reverse), and 5'-AGC-CATGTA-CGT-AGC-CAT-CC-3' (forward) and 5'-CTC-TCA- GCT-GTGGTG-GTG-AA-3' (reverse) were used for $\beta$-actin.

\section{Statistical Analysis}

Statistics used means and standard error for continuous variables. A repeated-measurements analysis was conducted to evaluate the main effects of stimulation with the covariate among repeated measures modeled as compound symmetry. All comparisons were 2-tailed. All statistical analyses were performed with SAS software, version 9.2 (SAS Institute Inc, Cary, NC), and Stat View, version 5 (Abacus Inc, Berkeley, Calif).

\section{RESULTS}

\section{Changing Morphology of the Remnant Lung}

After PNX, volume and wet weight of the remnant right lung were examined periodically. Body weight did not differ significantly between the pneumonectomized rats and the sham control throughout the experimental period (Figure 1,A). Chest x-ray revealed that the mediastinal shift occurred the day after pneumonectomy. Seven days after surgery, the mediastinum of each pneumonectomized rat had completely shifted to the left, and the remnant right
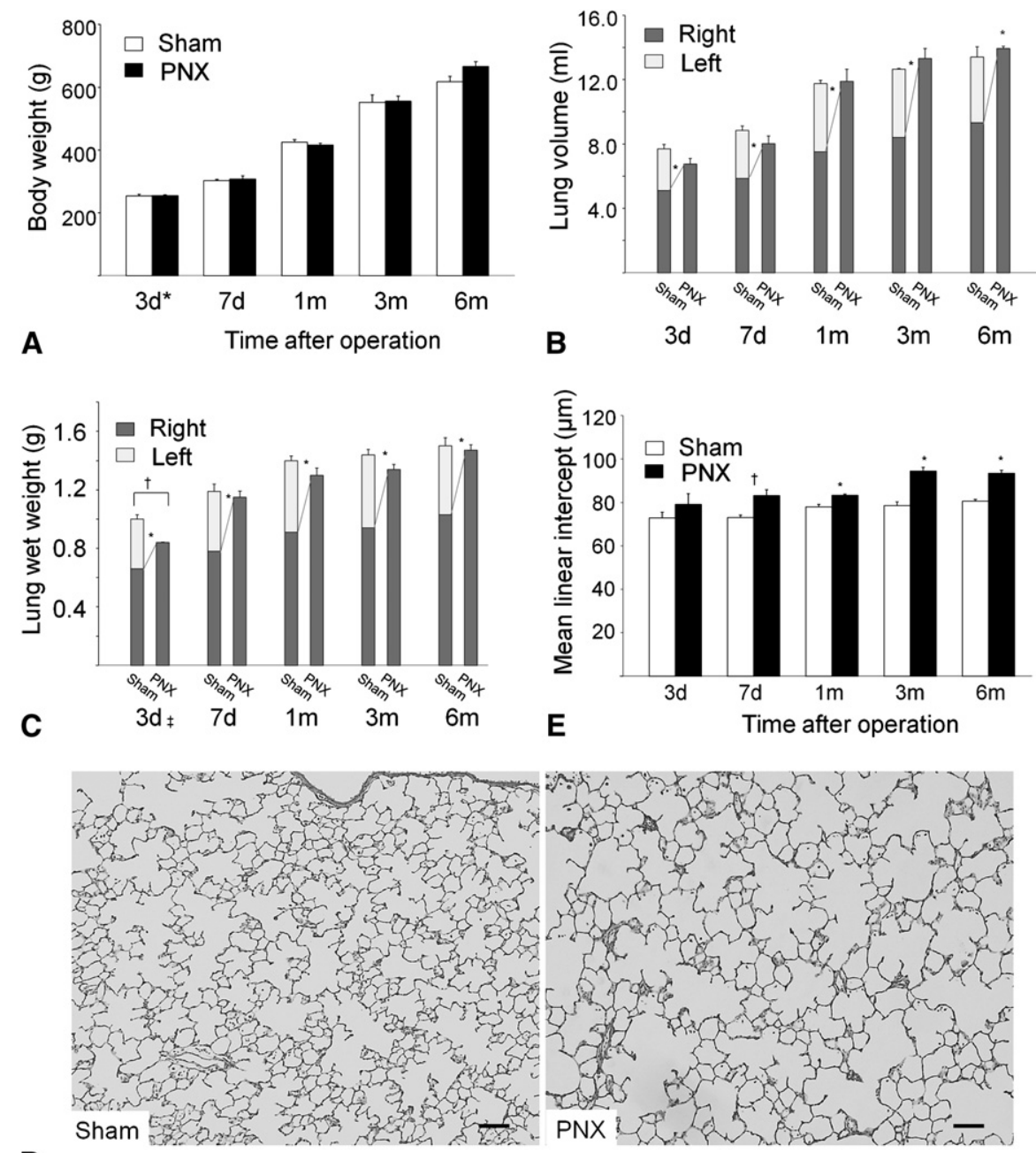

D

FIGURE 1. CLG was evaluated in the right lung after PNX and in the total lung after a sham operation. A, Body weights of the rats were not significantly different throughout the experimental period $(n=6, * n=3)$. B, The lung volume in the right lung increased significantly in the pneumonectomized rats in comparison with the right lung of sham-operated rats at every time point $(\mathrm{n}=3)$. $* P<.05$. The remnant right lung volume of pneumonectomized rats and the total lung volume of sham controls were not significantly different 3 days after surgery. $\mathrm{C}$, The wet lung weight in the right lung was significantly greater in the pneumonectomized rats in comparison with the right lung of sham controls at every time point $(\mathrm{n}=6, \ddagger \mathrm{n}=3)$. $* P<.01$. The remnant right lung weights were significantly lighter than those of the total lungs of sham controls 3 days after surgery; however, there was no significant difference between the groups 7 days after surgery. $\dagger P<.05$. Morphologic changes during CLG in the right lung after pneumonectomy or sham operation were assessed. The average airspace distance (Lm) was determined in both groups at each time point. D, Histologic appearance of HE-stained tissues showed that alveolar spaces including alveoli and alveolar ducts of pneumonectomized rat appeared to enlarge more than those of sham controls 7 days after surgery (scale bars, $100 \mu \mathrm{m}$ ). E, The Lm of the pneumonectomized rats was larger than those of sham controls. $* P<.05, \dagger P=.052(\mathrm{n}=3,30$ fields for each animal). All data are shown as mean values \pm standard error. $P N X$, Pneumonectomy. 
lung became overinflated (data not shown). Both the wet weight and volume of the remnant right lung after pneumonectomy were significantly greater than those in the sham group at each time point. The remnant right lung volume in the pneumonectomized rats did not have significant difference from that of the total (right and left) lungs in the sham control 3 days after surgery and kept increasing throughout the observation period in accordance with normal growth. With regard to lung wet weight, the remnant lung after pneumonectomy was significantly lighter than the total lungs in the sham control 3 days after surgery. However, the statistical significance of the difference between the groups was lost after 7 days (Figure 1, B,C).

On histologic examination of HE-stained tissue, alveolar spaces including alveoli and alveolar ducts of the pneumonectomized rats appeared to enlarge more than those of the sham controls at each time point (Figure $1, D$ ). The mean values of $\mathrm{Lm}$ in pneumonectomized rats were larger in comparison with those of sham controls, especially 1,3 , and 6 months after surgery (Figure 1,E).

\section{Gene Expression Profiles in the Remnant Lungs of Pneumonectomized Rats}

To analyze the molecular mechanisms of the phenomenon in the remnant right lung, gene expression was analyzed twice at each time point ( 3 or 7 days, and 1, 3, or 6 months). Gene expression data were obtained by microarray analysis of the remnant lung and interpreted by comparison with the data obtained from the resected left lung of the same rat. Microarray data sets in the same period were reproducible $(r>$ 0.958, Pearson product-moment correlation coefficient). Thus, we used one set of data for the following analyses.

Of the 26,208 genes in the remnant right lung, expression of $2.2 \%$ to $8.3 \%$ of the genes changed more than 2 -fold or less than one half those of the control left lung during the experimental period. In that group of genes, changes greater than 2-fold were observed in 453, 83, 265,162 , and 1093 genes in the right lung compared with the left lung after 3 or 7 days, or 1, 3, or 6 months after pneumonectomy, respectively. The cutoff intensity was 1000 because it could be resolved from the background signal. For these genes, GSEA ${ }^{14}$ was performed, and gene sets that contained genes significantly up-regulated at least 2-fold at each time point are shown in Table E1. Gene sets that were prevalent during lung regeneration (including cell division, cell proliferation, cell cycle, and mitosis) increased significantly up to 1 week after surgery; those expression changes were lost at later periods. In a heat map, the up-regulation of the gene ontology set for cell division was recognized immediately after pneumonectomy (days 3 and 7) (Figure 2, A). Expression of genes related to angiogenesis increased after 1 month, and those related to inflammatory responses increased at every time point for 6 months after surgery (Figure 2, B, $C)$ with statistical significance in GSEA (Table E1). Up-regulation of genes involved with development, differentiation, and proliferation of the nervous system (Prph, Somaphorin 3D, Isll, and Sox6), vessels (Fgf9, Lepr, and $I l l b)$, and pleura $(M s l n)$ was remarkable at each time point (Table E2). In contrast, expression of genes involved in alveogenesis (thyroid transcription factor-1, Gata6) did not change. In a heat map, the gene ontology set of lung alveolus development also showed no change (Figure 2,D). The above results suggested that post-pneumonectomy CLG is mainly supported by remodeling of interstitial structures.

\section{Lung Cells Enriched in Alveolar Type II Cells Successfully Engrafted in the Remnant Lung After Pneumonectomy}

Next, we investigated whether supplementation of cell sources for alveoli (ATIIs) promoted alveolar regeneration. ATII populations were enriched as previously described (Figure 3, A). Cell viabilities averaged $90 \%$, and the purity of freshly isolated ATIIs assessed by double staining with surfactant protein $C$ and DAPI was greater than $84 \%$ $(\mathrm{n}=4)$ (Figure 3, B, C). Transmission electron microscopy demonstrated lamellar bodies and microvilli (Figure 3, D) of isolated cells that are characteristic of ATIIs. Endotracheal instillation of the fresh lung cells into pneumonectomized rats was performed without problems and did not cause pneumonia or life-threatening lung edema. There was no significant difference of body weight among pneumonectomized rats with respect to instillation of lung cells (Figure E1).

We determined whether freshly instilled lung cells were successfully integrated into recipient alveoli by Y-FISH by using a sex-mismatch model. Y-FISH-positive signals were always absent in the female controls and always present in the male controls (Figure 4, A, B). In female recipients instilled with male donor-derived lung cells, Y-FISHpositive signals were detected in cells that constituted the alveolar epithelium and bronchiole 1 month after transplantation (Figure 4, $C, D$ ). In addition, engraftment levels of male donor-derived cells in the lungs of female recipients 1 month after transplantation were quantified by real-time PCR assessment of the Sry gene on the Y-chromosome. The Sry gene was not detected in the female negative control and was always detected in the positive male controls. In pneumonectomized female rats 1 month after transplantation of male lung cells, the values of Sry normalized to $\beta$-actin were $0.09 \%$ to $17.6 \%$ of that of the average values in male controls. Sry was not detected in sham-operated controls despite instillation of lung cells (Figure 4, E). The variability of the expression level was likely due to experimental inconsistencies in the distribution of instilled lung cells. 


\section{$3 d 1 \mathrm{w} 1 \mathrm{~m} 3 \mathrm{~m} 6 \mathrm{~m}$}

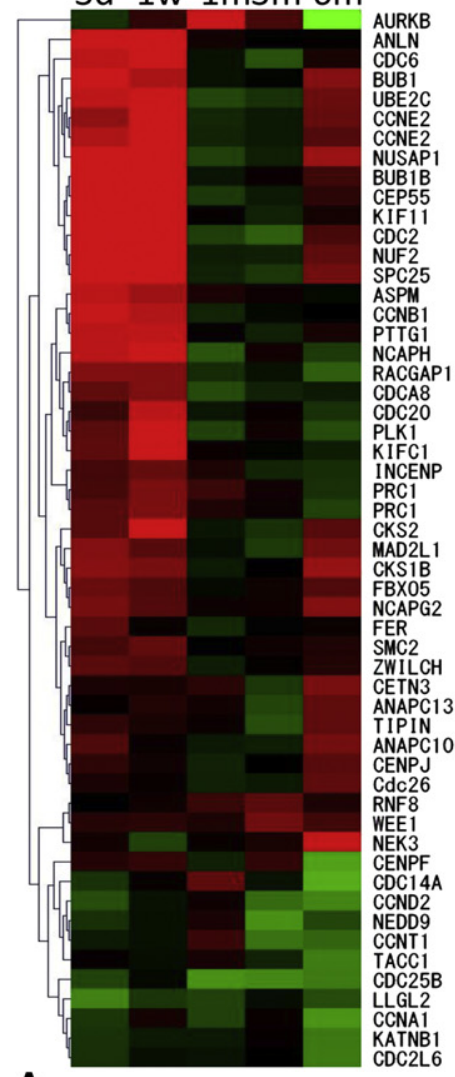

A

Fold change, Log 2

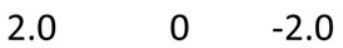

$3 d 1 w 1 m 3 m 6 m$

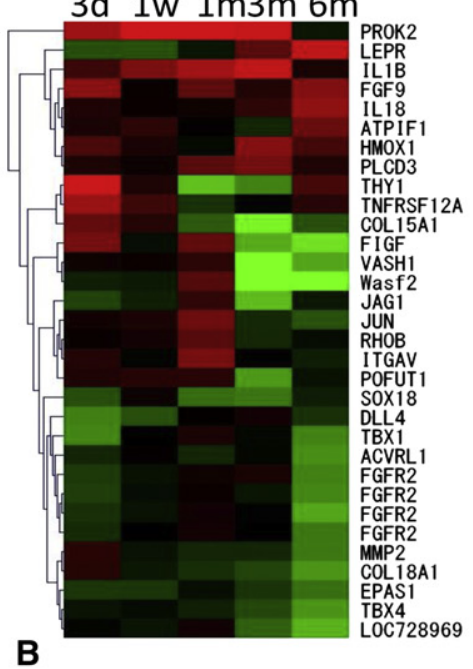

$3 d 1 \mathrm{w} 1 \mathrm{~m} 3 \mathrm{~m} 6 \mathrm{~m}$

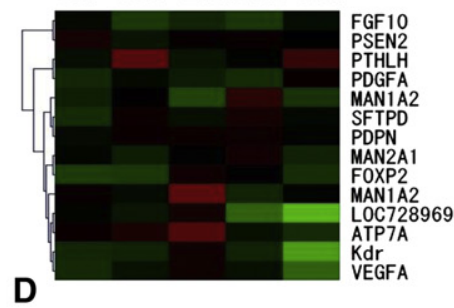

$3 \mathrm{~d} 1 \mathrm{w} 1 \mathrm{~m} 3 \mathrm{~m} 6 \mathrm{~m}$

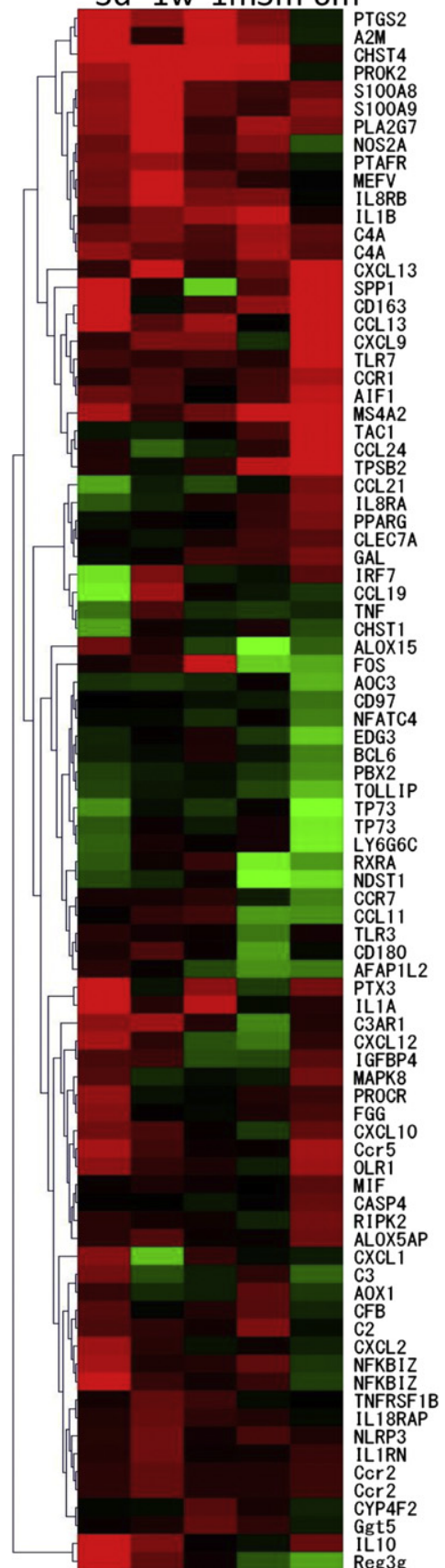

FIGURE 2. Expression of genes involved with each gene ontology (GO) set is expressed as heat maps with time after surgery. Color bar represents foldchanges of gene expression in the right lung compared with the control left lung on a $\log _{2}$ scale. Each figure shows the genes involved with each GO term below. A, Cell division, defined as the process resulting in the physical partitioning and separation of a cell into daughter cells, GO: 0051301, $\mathrm{n}=54$. B, Angiogenesis, defined as blood vessel formation when new vessels emerge from the proliferation of preexisting blood vessels, GO: 0001525, $\mathrm{n}=32$. C, Inflammatory change, defined as the immediate defensive reaction to infection or injury caused by chemical or physical agents whose process is characterized by local vasodilation, extravasation of plasma into intracellular spaces, and accumulation of white blood cells and macrophages, GO: 0006954, $\mathrm{n}=87$. D, Lung alveolar development, defined as the process whose specific outcome is the progression of the alveolus over time, from its formation to the mature structure, GO: 0048286, $\mathrm{n}=14$. The gene numbers represent the numbers of genes included in each GO term. A, Gene sets that related to cell division increased significantly up to 1 week after surgery, but those gene expression changes were lost at later periods. B, Expression of genes related to angiogenesis increased after 1 month. C, Expression of genes related to inflammatory responses increased at every time point for 6 months after surgery. D, Expression of genes related to lung alveolar development showed no change. 


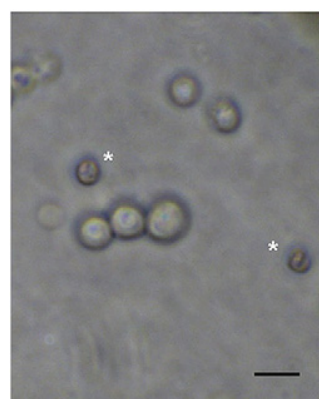

A

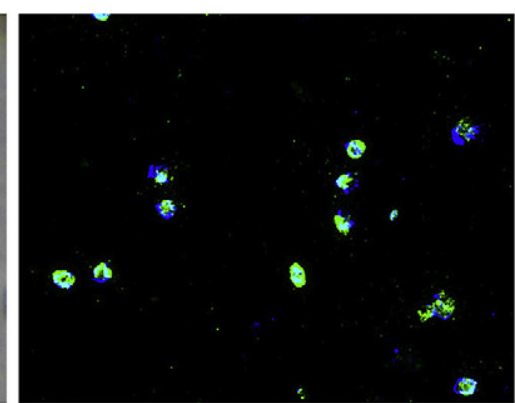

B

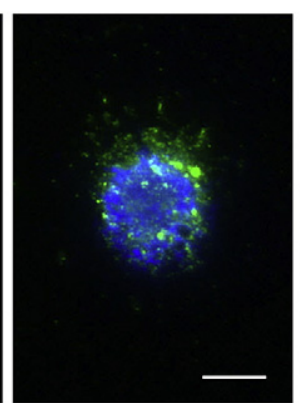

C

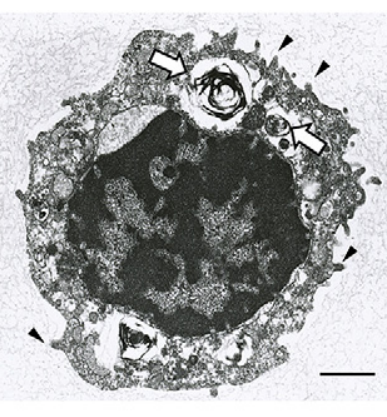

D

FIGURE 3. Isolated cells had features of ATIIs. A, Light microscopic imaging of isolated cells. Asterisk denotes red blood cells (scale bar, $10 \mu \mathrm{m}$ ). B, C, Immunofluorescence staining showing ATIIs with surfactant protein C (green). DAPI stained the nucleus (blue, scale bar, $5 \mu \mathrm{m}$ ). D, Transmission electron micrograph showing ATIIs with lamellar bodies (white arrows) and microvilli (arrowheads) (scale bar, $1 \mu \mathrm{m})$.

\section{Endotracheal Instillation of Lung Cells Enriched in Alveolar Type II Cells Influenced Compensatory Lung Growth}

$\mathrm{Lm}$ values and body weights were significantly correlated in pneumonectomy and sham groups (PNX group: $\rho=0.704, P=.0085$; sham group: $\rho=0.800$, $P=.0028$ ) (Figure 5,A). The slope of the line for the PNX group nearly paralleled that of the sham group, perhaps suggesting natural alveolar growth during the maturation process. The value of $\mathrm{Lm}$ should have decreased, which means the alveolar density should have increased if regeneration of new lung tissue had been occurring. These results suggest that hyperinflation of the existing lung structure compensated for the loss of resected lung tissue, and that growth of alveolar elements, except for maturation, was not observed after pneumonectomy in adult rats. However, in lung cell-instilled pneumonectomized rats, Lm was significantly lower than that in untreated pneumonectomized rats $(P=.0004)$ and almost equivalent to that in sham control rats $(P=.946)$ by analysis of covariance (Figure 5, $A$, $B)$. HE staining of lung cell-instilled pneumonectomized rats showed dense alveolar structures that were equivalent to that of sham controls (Figure 5, C). These results suggest that instillation of lung cells enriched in ATIIs contributed to alveolar regeneration.

\section{DISCUSSION}

The present study investigated the morphology and mRNA profiles in remnant lungs after pneumonectomy and demonstrated that post-pneumonectomy CLG depends mainly on enlargement of existing lung tissue. The histology showed that alveolar spaces were always larger in the pneumonectomized rats than in the sham controls. The mRNA profiles demonstrated that cell proliferation was limited to the first week of CLG. Gene expression was up-regulated in inflammatory, angiogenic, and neurogenic pathways, but not in alveogenesis. Thus, hyperplasia (and hyperinflation) of the existing lung structure is the primary response after pneumonectomy. Furthermore, the principle response of CLG appears to be remodeling of interstitial structures and not generation of new pulmonary alveoli. Consequently, we hypothesized that regeneration of lung alveoli requires supplemental cell sources (stem/progenitor cells) of alveoli in the remnant lung. We then tested the concept that endotracheal instillation of ATIIs (epithelial progenitors of alveoli) could stimulate lung regeneration.

We confirmed that lung volume and weight in the remnant lung increased to compensate for the loss of lung mass for the first week after pneumonectomy, as shown previously. ${ }^{1,17-19}$ However, it is not clear whether regeneration of new lung tissue occurred. In addition to the increased size of existing alveoli, some investigators demonstrated that neoalveolarization contributes to restoration of gas exchange area after pneumonectomy. ${ }^{17,18}$ However, the degree of neoalveolarization depends on the experimental model. The number of alveoli and alveolar surface density is lower after pneumonectomy than in sham controls. ${ }^{17,19}$ New growth of alveoli might have occurred in the early phase of CLG, but it was too slight to detect in our experimental design. In addition, the sex-mismatch model demonstrated that transplanted lung cells successfully engrafted in the lung tissues, leading to maintenance of normal alveolar density with Lm even after pneumonectomy. Thus, lung cell transplantation stimulated lung regeneration during CLG after pneumonectomy.

Previous studies of post-pneumonectomy gene expression in CLG have focused on specific pathways rather than global transcriptomic patterns over a short-term period. Gilbert and Rannels ${ }^{20}$ described a rapid and transient up-regulation of $c$-fos and JunB within 30 minutes of pneumonectomy in rats. Landesberg and colleagues ${ }^{21}$ demonstrated up-regulation of 6 genes, including Egrl, $\mathrm{Nr} 4 \mathrm{al}$ (also known as Nurr77), Zfp36 (also known as Tristetraprolin), Nfkbia, and Klf-4 (also known as Gklf), within 2 hours of pneumonectomy in mice. The more recent study 

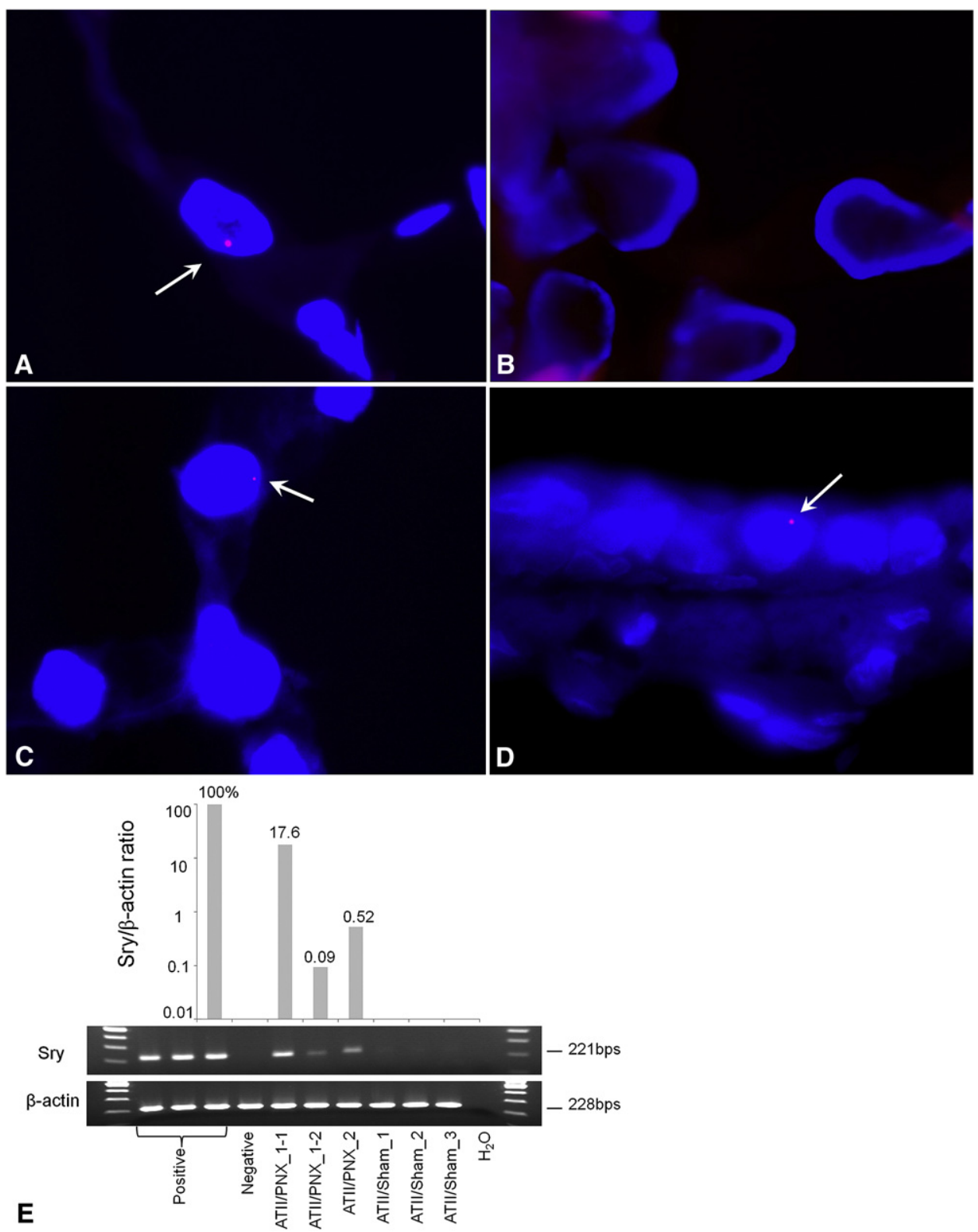

FIGURE 4. Freshly instilled lung cells enriched in ATIIs successfully engrafted in the remnant lung after pneumonectomy. A, Male positive controls showed Y-FISH-positive signals in alveolar cells. B, Y-FISH-positive cells were absent in alveolar cells of female negative controls. C, D, Detection of donor-derived lung cells by Y-FISH in female recipients 1 month after transplantation. Y-FISH-positive cells (arrows) were demonstrated in the alveolar wall (C) and bronchiole (D). Nuclei were counterstained with DAPI (blue). E, Quantification of male ATIIs engraftment in female rat lungs by real-time PCR. Histogram of the data obtained in the real-time PCR shows the value of Sry normalized to $\beta$-actin. The value on the histogram represents the ratio for the average values in male controls. The positive and negative controls were rat lungs from male and female rats, respectively. ATII/PNX: pneumonectomized rat that was instilled with ATIIs endotracheally. ATII/PNX-1_1 and ATII/PNX-1_2: samples from different lobes of the same rat. ATII/Sham: sham operation in which rat was instilled with ATIIs. Engraftment of ATIIs is demonstrated in pneumonectomized rats but not in sham controls. The vertical axis shows logarithmic display.

indicated the influential role of thyroid transcription factor1 (also known as $N k \times 2-1$ ) in modulating the early phase of murine CLG within the first 2 days. ${ }^{18}$ In our results, these genes hardly changed throughout the study period (Table E2). These differences could be due to the time points chosen for analysis. In support of our results, Paxson and colleagues $^{22}$ analyzed global gene expression patterns and found that adult alveolar regeneration was not identical to lung alveolar growth after pneumonectomy 1 week after surgery. The proliferative response documented in our mRNA profiling is also consistent with the rapid lung growth of remnant lung after major lung resection. ${ }^{1}$ 

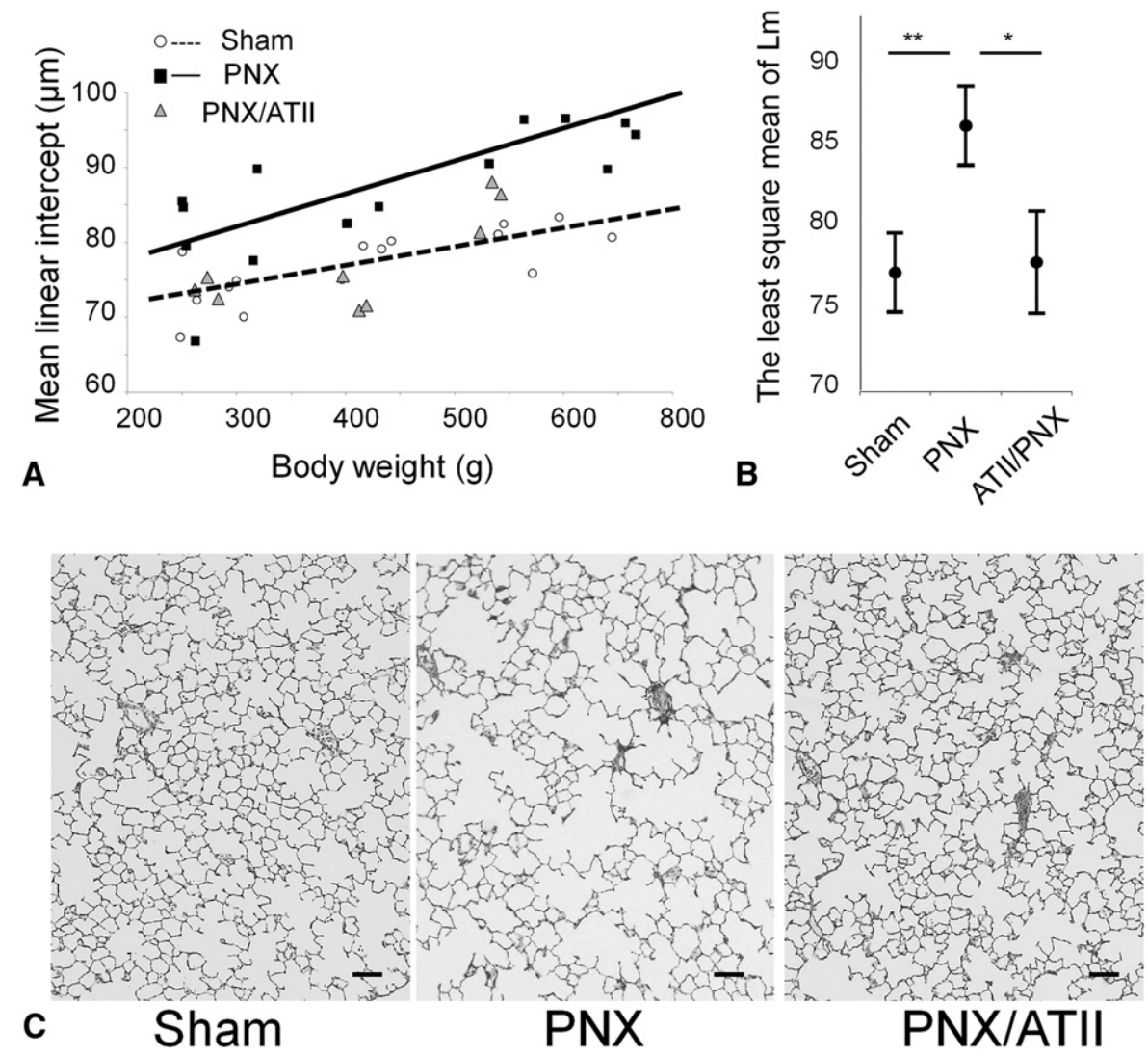

FIGURE 5. Transplantation of isolated lung cells enriched in ATIIs contributes to regeneration of alveoli in the lung after pneumonectomy. A, Correlation of $\mathrm{Lm}$ and body weight. The $\mathrm{Lm}$ and body weights were well correlated in both groups (PNX group: $\rho=0.704, P=.0085$; sham group: $\rho=0.800$, $P=.0028$ ). Although the growth of pulmonary elements, except for maturation, was not identified after pneumonectomy alone, the Lm decreased in the pneumonectomized rats treated with lung cell transplantation. B, Covariance of analysis with body weight as a covariate showed that the least square mean of Lm in lung cell-instilled pneumonectomized rats was significantly lower than that of pneumonectomized rats $(* P=.0004)$ and almost equivalent to that in sham control rats $(P=.946)$. In addition, that in sham control was significantly lower than that in pneumonectomized rats $(* * P<.0001)$. Confidence interval of each group was $95 \%$. C, Seven days after surgery, alveolar density of the pneumonectomized rats with lung cell transplantation is higher than that of the pneumonectomized rats and equal to that of sham controls (scale bar, $100 \mu \mathrm{m}$ ). ATII, Alveolar type II cell; PNX, pneumonectomy.

The mechanism of alveolar regeneration is unknown, and several explanations are possible. First, ATIIs, which comprise a large portion of isolated lung cells, are progenitors of alveolar epithelium and can convert to alveolar type I cells after injury. They also have an important role in stabilizing the water balance between intracellular and extracellular fluids in the alveoli after pneumonectomy. The availability of endogenous ATIIs after pneumonectomy was apparently insufficient, and transplantation of ATIIs may have restored this pool, increasing the number of alveolar cells capable of regenerating new alveolar tissue and stabilizing the pulmonary environment. Second, the remarkable proliferative response that was demonstrated in this study may have enabled the instilled lung cells to proliferate within 1 week of pneumonectomy. Third, other progenitor cells, such as BASCs and Clara cells, may have been present and contributed to regeneration of new lung tissue. Instilled lung cells were demonstrated in bronchioles of recipient rats.
In previous studies in porcine and sheep models, mature pulmonary lobar transplants grew in an immature environment, ${ }^{23,24}$ and a recent study postulated that the same phenomenon occurs in humans. ${ }^{25}$ Thus, cessation of alveolar multiplication is reversible under the proper conditions. Post-pneumonectomy, proliferation occurs rapidly, and interstitial tissue undergoes remodeling and regeneration. It is likely that all of these conditions are required for alveolar regeneration, which enables transplanted lung cells to engraft and regenerate alveoli. In this study, the 7- to 8week-old adult rats showed significant growth of the lung and thorax because epiphyseal closing does not occur in rats. The process of natural lung growth may have influenced alveolar regeneration by instilled lung cells. However, because the instilled lung cells did not engraft in the sham operated rats, pneumonectomy is the most important factor for lung cell engraftment.

In this study, we have proposed that lung function is almost parallel to morphology even after pneumonectomy, 
although it remains to be further clarified. According to this rationale, transplantation of cells of ATIIs may offer a therapeutic procedure for the preservation or enhancement of function in the remnant lung after lung resection in the adult. As to translational research for cell therapy, human ATIIs prepared from clinically resected lung specimen are now investigated for the ability to differentiate to alveolar type I cells in vitro and to survive in the remnant lungs of immunocompromised rodents after pneumonectomy.

\section{CONCLUSIONS}

We postulate that lung cell transplantation stimulates lung regeneration in the remnant lung after pneumonectomy in mature rats. Although further studies will be needed to apply this concept in a clinical setting, we believe this study contributes to our understanding of regenerative medicine of the human lung.

The authors thank the staff of the Department of General Thoracic Surgery, Graduate School of Medicine, Chiba University; Eri Satoh for technical assistance with molecular experiments; and Fumie Saegusa and Yoko Hata for support with histologic studies.

\section{References}

1. American Thoracic Society. Mechanisms and limits of induced postnatal lung growth. Am J Respir Crit Care Med. 2004;170:319-43.

2. Sakamaki Y, Matsumoto K, Mizuno S, Matsuda H, Nakamura T. Hepatocyte growth factor stimulates proliferation of respiratory epithelial cells during postpneumonectomy compensatory lung growth in mice. Am J Repir Cell Mol Biol. 2002;26:525-33.

3. Matsumoto K, Nagayasu T, Hishikawa Y, Tagawa T, Yamayoshi T, Abo T, et al. Keratinocyte growth factor accelerates compensatory growth in the remaining lung after trilobectomy in rats. J Thorac Cardiovasc Surg. 2009;137:1499-507.

4. Sakurai MK, Lee S, Arsenault DA, Nose V, Wilson JM, Heymach JV, et al. Vascular endothelial growth factor accelerates compensatory lung growth after unilateral pneumonectomy. Am J Physiol Lung Cell Mol Physiol. 2007;292:L742-7.

5. Kaza AK, Kron IL, Kern JA, Long SM, Fiser SM, Nguyen RP, et al. Retinoic acid enhances lung growth after pneumonectomy. Ann Thorac Surg. 2001;71: 1645-50.

6. Sage EK, Loebinger MR, Polak J, Janes SM. The role of bone marrow-derived stem cells in lung regeneration and repair. In: Bhatia S, ed. Stembook. Cambridge, MA: Harvard Stem Cell Institute; 2008:1-13.

7. Voswinckel R, Ziegelhoeffer T, Heil M, Kostin S, Breire G, Mehling T, et al. Circulating vascular progenitor cells do not contribute to compensatory lung growth. Circ Res. 2003;93:372-9.
8. Nolen-Walston RD, Kim CF, Mazan MR, Ingenito EP, Gruntman AM, Tsai L, et al. Cellular kinetics and modeling of bronchioalveolar stem cell response during lung regeneration. Am J Physiol Lung Cell Mol Physiol. 2008;294: L1158-65.

9. Griffiths MJ, Bonnet D, Janes SM. Stem cells of the alveolar epithelium. Lancet. 2005;366:249-60.

10. Serrano-Mollar A, Nacher M, Gay-Jordi G, Closa D, Xaubet A, Bulbena O. Intratracheal transplantation of alveolar type II cells reverses bleomycin-induced lung fibrosis. Am J Respir Crit Care Med. 2007;176:1261-8.

11. Wang D, Morales JE, Calame DG, Alcorn JL, Wetsel RA. Transplantation of human embryonic stem cell-derived alveolar epithelial stem type II cells abrogates acute lung injury in mice. Mol Ther. 2010;18:625-34.

12. Scherle W. A simple method for volumetry of organs in quantitative stereology Mikroskopie. 1970;26:57-60.

13. Parameswaran H, Majumdar A, Ito S, Alencar AM, Suki B. Quantitative characterization of airspace enlargement in emphysema. J Appl Physiol. 2006;100: 186-93.

14. Subramanian A, Tamayo P, Mootha VK, Mukherjee S, Ebert BL, Gillette MA et al. Gene Set Enrichment Analysis: a knowledge based approach for interpreting genome wide expression profiles. Proc Natl Acad Sci U S A. 2005;102: 15545-50.

15. Gene Ontology Consortium. The gene ontology (GO) project in 2006. Nucleic Acids Res. 2006;1:D322-6.

16. Richards DJ, Davies N, Atkins J, Oreffo VI. Isolation, biochemical characterization, and culture of lung type II cells of the rat. Lung. 1987;165:143-58.

17. Fehrenbach H, Voswinchel R, Michl V, Mehling T, Fehrenbach A, Seeger W, et al. Neoalveolarisation contributes to compensatory lung growth following pneumonectomy in mice. Eur Respir J. 2008;31:515-22.

18. Takahashi Y, Izumi Y, Kohno M, Kimura T, Kawamura M, Okada Y, et al. Thyroid transcription factor-1 influences the early phase of compensatory lung growth in adult mice. Am J Respir Crit Care Med. 2010;181:1397-406.

19. Fernandez LG, Mehta CK, Kron IL, Laubach VE. Reinitiation of compensatory lung growth after subsequent lung resection. J Thorac Cardiovasc Surg. 2007; 134:1300-5

20. Gilbert KA, Rannels DE. Increased lung inflation induces gene expression after pneumonectomy. Am J Physiol. 1998;25:L21-9.

21. Landesberg LJ, Ramalingam R, Lee K, Rosengart TK, Crystal RG. Upregulation of transcription factors in lung in the immediate phase of post-pneumonectomy lung growth. Am J Physiol Lung Cell Mol Physiol. 2001;281:L1138-49.

22. Paxson JA, Parkin CD, Iyer LK, Mazan MR, Ingenito EP, Hoffman AM. Global gene expression patterns in the post-pneumonectomy lung of adult mice. Respir Res. 2009;10:92

23. Binns OA, DeLima NF, Buchanan SA, Lopes MB, Cope JT, Marek CA, et al. Mature pulmonary lobar transplants grow in an immature environment. $J$ Thorac Cardiovasc Surg. 1997;114:186-94.

24. Ibla JC, Shamberger RC, DiCanzio J, Zurakowski D, Koka BV, Lillehei CW. Lung growth after reduced size transplantation in a sheep model. Transplantation. 1999;67:233-40.

25. Toyooka S, Sano Y, Yamane M, Oto T, Okazaki M, Kusano KF, et al. Longterm follow-up of living-donor single lobe transplantation for idiopathic pulmonary arterial hypertension in a child. J Thorac Cardiovasc Surg. 2008;135 451-2. 


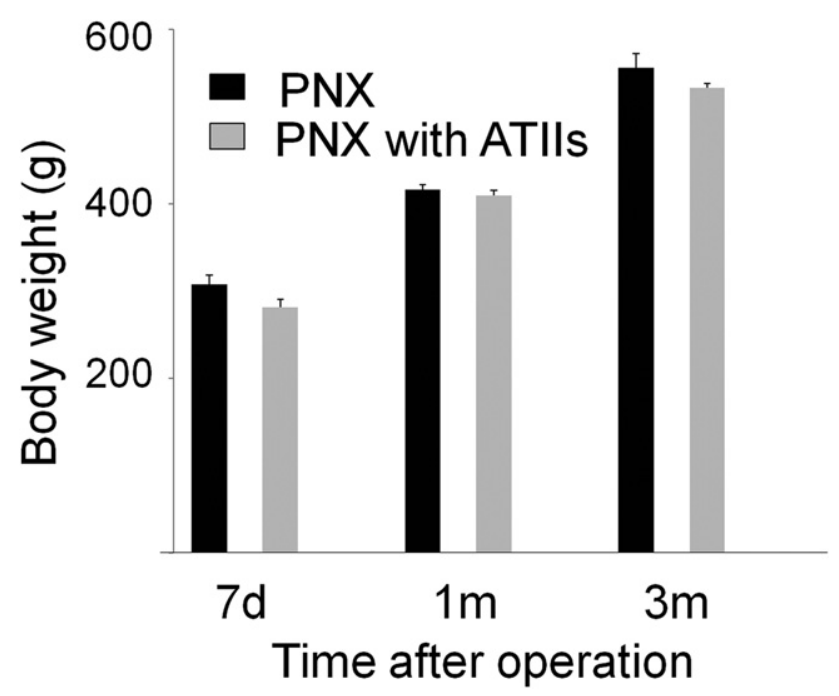

FIGURE E1. Body weights of rats that underwent PNX did not differ from those of rats that underwent PNX with ATIIs transplantation at every time point. ATII, Alveolar type II cell; PNX, pneumonectomy. 
TABLE E1. Gene Set Enrichment Analysis of genes showing more than a two-fold difference in their expression

\begin{tabular}{|c|c|}
\hline Gene set & $\begin{array}{c}\text { Bonferroni } \\
\text { corrected } \\
\text { p-value } \\
\end{array}$ \\
\hline \multicolumn{2}{|l|}{$3 \mathbf{d}$} \\
\hline Inflammatory response & $7.07 \times 10^{14}$ \\
\hline Cell adhesion & $1.02 \times 10^{11}$ \\
\hline Mitosis & $1.70 \times 10^{11}$ \\
\hline Cell division & $3.03 \times 10^{11}$ \\
\hline Cell cycle & $5.13 \times 10^{10}$ \\
\hline Protein binding & $4.14 \times 10^{7}$ \\
\hline Cell proliferation & $6.62 \times 10^{7}$ \\
\hline Heparin binding & $1.53 \times 10^{4}$ \\
\hline Positive regulation of cell proliferation & $5.10 \times 10^{4}$ \\
\hline Phosphate transport & $5.34 \times 10^{4}$ \\
\hline Cell-cell signaling & $8.59 \times 10^{4}$ \\
\hline Immune response & $1.28 \times 10^{3}$ \\
\hline Extracellular matrix structural constituent & $2.06 \times 10^{3}$ \\
\hline Tissue regeneration & $4.96 \times 10^{3}$ \\
\hline Blood circulation & $6.69 \times 10^{3}$ \\
\hline Cell-matrix adhesion & $3.29 \times 10^{2}$ \\
\hline \multicolumn{2}{|l|}{1 wk } \\
\hline Cell cycle & $2.45 \times 10^{26}$ \\
\hline Mitosis & $5.41 \times 10^{21}$ \\
\hline Cell division & $2.13 \times 10^{18}$ \\
\hline Immune response & $2.02 \times 10^{11}$ \\
\hline Inflammatory response & $5.49 \times 10^{9}$ \\
\hline DNA replication & $8.84 \times 10^{8}$ \\
\hline Protein binding & $3.83 \times 10^{7}$ \\
\hline Cell proliferation & $1.03 \times 10^{6}$ \\
\hline Cytokinesis & $1.48 \times 10^{5}$ \\
\hline ATP binding & $1.47 \times 10^{4}$ \\
\hline DNA-dependent ATPase activity & $1.18 \times 10^{3}$ \\
\hline Chemotaxis & $2.06 \times 10^{3}$ \\
\hline Regulation of cyclin-dependent protein kinase activity & $6.94 \times 10^{3}$ \\
\hline DNA replication initiation & $9.38 \times 10^{3}$ \\
\hline \multicolumn{2}{|l|}{1 mo } \\
\hline Double-stranded DNA binding & $1.18 \times 10^{5}$ \\
\hline Regulation of cell cycle & $3.20 \times 10^{5}$ \\
\hline Cell adhesion & $1.54 \times 10^{2}$ \\
\hline Inflammatory response & $2.87 \times 10^{2}$ \\
\hline Angiogenesis & $3.27 \times 10^{2}$ \\
\hline \multicolumn{2}{|l|}{3 mo } \\
\hline Iron ion binding & $4.54 \times 10^{5}$ \\
\hline Heme binding & $5.28 \times 10^{4}$ \\
\hline Metabolic process & $5.38 \times 10^{4}$ \\
\hline Inflammatory response & $5.46 \times 10^{4}$ \\
\hline Oxidoreductase activity & $3.79 \times 10^{3}$ \\
\hline Retinol metabolic process & $4.69 \times 10^{3}$ \\
\hline Complement activation, classic pathway & $9.50 \times 10^{3}$ \\
\hline Retinoic acid metabolic process & $1.28 \times 10^{2}$ \\
\hline Calcium ion binding & $2.99 \times 10^{2}$ \\
\hline \multicolumn{2}{|l|}{$6 \mathrm{mo}$} \\
\hline Structural constituent of ribosome & $3.87 \times 10^{24}$ \\
\hline Translation & $1.30 \times 10^{21}$ \\
\hline Protein binding & $2.23 \times 10^{8}$ \\
\hline
\end{tabular}

TABLE E1. Continued

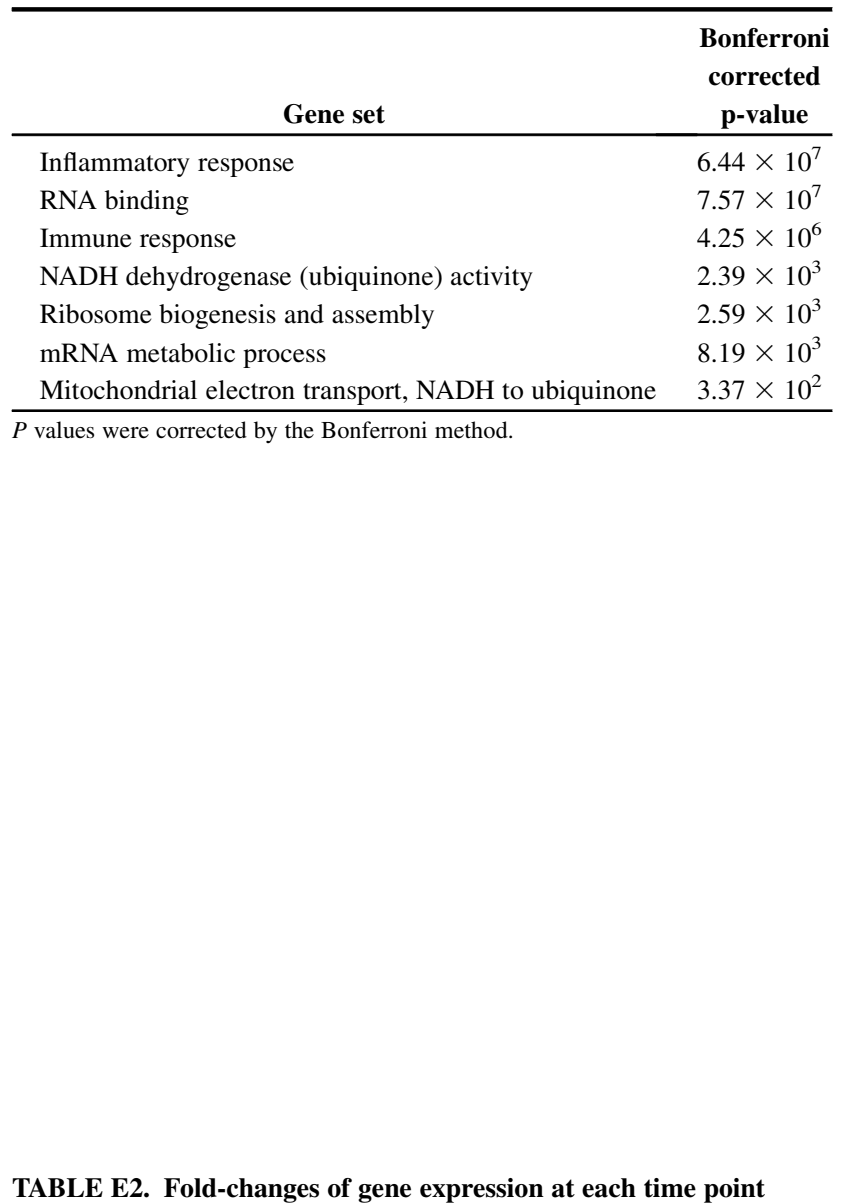

TABLE E2. Fold-changes of gene expression at each time poin

\begin{tabular}{|c|c|c|c|c|c|}
\hline & $3 \mathrm{~d}$ & $7 \mathrm{~d}$ & $1 \mathrm{mo}$ & $3 \mathrm{mo}$ & $6 \mathrm{mo}$ \\
\hline \multicolumn{6}{|l|}{ Nervous system } \\
\hline Prph & 18.70 & 7.20 & 19.92 & 9.84 & 2. \\
\hline Semaphorin-3D & 3.54 & 2.20 & 4.92 & 12.59 & 1.0 \\
\hline Isll & 11.20 & 3.85 & 9.19 & 31.15 & 23.2 \\
\hline Sox6 & 5.07 & 4.75 & 0.71 & 1.90 & 2. \\
\hline \multicolumn{6}{|l|}{ Vessel } \\
\hline$F g f 9$ & 2.76 & 1.08 & 2.09 & 1.35 & 2. \\
\hline Lepr & 0.60 & 0.59 & 0.86 & 2.02 & 3.7 \\
\hline$I l 1 b$ & 1.65 & 2.53 & 3.16 & 3.78 & 1. \\
\hline \multicolumn{6}{|l|}{ Pleura } \\
\hline$M \operatorname{sln}$ & 6.20 & 1.88 & 4.60 & 10.37 & 0.7 \\
\hline \multicolumn{6}{|l|}{ Alveolus } \\
\hline$N k x 2-1$ & 0.75 & 1.09 & 0.83 & 0.54 & 0. \\
\hline Gata6 & 0.91 & 0.93 & 1.16 & 0.62 & 0.9 \\
\hline Sftpc & 0.85 & 0.92 & 1.01 & 0.93 & 0.9 \\
\hline \multicolumn{6}{|l|}{ Others } \\
\hline$c-f o s$ & 1.21 & 1.50 & 4.54 & 0.31 & 0. \\
\hline JunB & 0.89 & 1.69 & 2.79 & 0.76 & 0.51 \\
\hline Egrl & 1.17 & 1.39 & 3.56 & 0.66 & 0.27 \\
\hline$N r 4 a 1$ & 1.48 & 2.47 & 4.40 & 0.62 & 0.40 \\
\hline Zfp36 & 1.25 & 0.79 & 1.82 & 0.85 & 0.36 \\
\hline Nfkbia & 1.12 & 0.94 & 0.86 & 0.98 & 0.8 \\
\hline$K l f-4$ & 0.85 & 0.91 & 1.12 & 0.83 & 0.74 \\
\hline
\end{tabular}

Data express fold-change of gene expression in the right lung after pneumonectomy compared with the left lung at each time point. 